\title{
PRIMEIROS TESTES DE COMUNICAÇÃO COM PROTOCOLO USB
}

\author{
Rafael Costa dos Santos, Germano Pinto Guedes \\ Bolsista Probic/UEFS, Graduando em Física Universidade Estadual de Feira de Santana \\ e-mail: rafaelc490@gmail.com \\ Orientador, Departamento de Física, Universidade Estadual de Feira de Santana \\ e-mail: germano@uefs.br
}

PALAVRAS-CHAVE: Arduino; Comunicação USB ; Aquisição de dados .

\section{INTRODUÇÃO}

Vários modelos teóricos tentam reproduzir o espectro solar após a passagem da radiação pelas camadas da atmosfera terrestre. Denominado Espectro Padrão, esta curva de referência é usada na calibração e análise de performance de vários materiais e dispositivos usados na conversão térmica e fotovoltaica [1,2] e sua definição parte se um espectro solar padrão (antes de passar na atmosfera terrestre) e considera condições e composição atmosféricas específicas, são elas: i) a atmosfera padrão (USSA) que especifica temperatura, pressão, densidade e composição molecular especificados para 33 camadas, a partir do nível do mar, mas que não considera aerossóis; ii) massa de ar de 1,5AM (air mass), que corresponde ao caminho óptico percorrido pela radiação solar a um ângulo zenital de 48,19 o ao nível do mar; iii) um caminho óptico com turbidez de 0,27 para feixe padrão monocromático de 500nm; iv) uma superfície de refletância espectral constante de 0,2 , assumindo que a superfície possui uma refletância do tipo cosseno (Lambertiana).

Dentre os modelos de transmissão atmosférica, os mais referenciados são o LOWTRAN, o MODTRAN, o SPECTRAL2 e o SMARTS2. Uma boa revisão sobre as técnicas e algoritmos usados nos cálculos de espectro solar pode ser encontrado em [2,3]. Sabe-se, no entanto que cada molécula presente na atmosfera é responsável por linhas, ou mesmo bandas, de absorção que removem do feixe principal fótons com comprimentos de onda específicos e que resulta na atenuação da intensidade do espectro $I(\lambda)$ registrado na terra. O modelo de transmissão atmosférica SPCTRAL2 tem como parâmetros de entrada a concentração de alguns gases e partículas, a latitude do local, o número do dia do ano, a inclinação e o azimute da superfície receptora de radiação solar e fornece como saída o espectro solar na superfície terrestre. Neste espectro são consideradas todas as possíveis absorções e espalhamentos que possam ocorrer decorrente da quantidade de vapor de água, aerossóis e ozônio na atmosfera. Por ser um modelo simples nos possibilita, a partir de dados de radiação direta, calcular as concentrações dos atenuadores da radiação tais como vapor de água, aerossóis e ozônio que estão presentes na atmosfera.

O objetivo deste trabalho é de construir um software que consiga coletar dados do espectrômetro Ocean Optics a cada 15 minutos via porta USB para registro e estudo do espectro solar. Neste processo de aprendizagem, tendo que trabalhar com a comunicação USB, neste primeiro período de bolsa, iniciamos estudo de linguagens de programação em $\mathrm{C}$ e Java para realizar testes de comunicação e criar um software de exibição gráfica visando a exibição das curvas dos espectros em tempo real.

\section{MATERIAIS E MÉTODOS}


Os primeiros testes de comunicação USB foram realizados com um dispositivo do tipo Arduino Uno[4] que foi programado em linguagem $C$ parar realizar medidas de temperatura com transmição de dados em tempo real e exibição gráfica em tela usando ferramentas de programação em linguagem Java[5]. A Figura1 mostra o esquema da montagem usando o sensor de temperatura LM35[6] cuja a sensisibilidade é de $10 \mathrm{mV} /{ }^{\circ} \mathrm{C}$. Esta montagem pode ser facilmente adaptada para qualquer outro tipo de medida como umidade, luminosidade, etc.

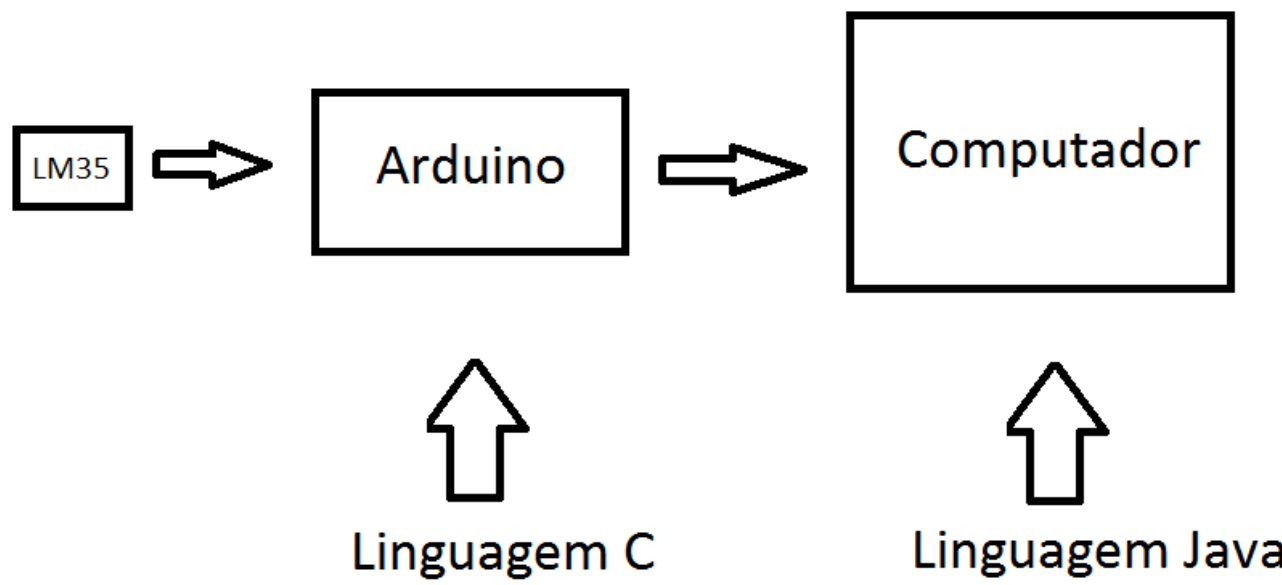

Figura1: Esquema da montagem utilizada para testes de comunicação USB entre o computador e o Arduino tomando dados de um sensor de temperatura LM35.

O firmware do Arduino é programado em C através de uma IDE (ambiente de programação) liberado do proprio fabricante, desta forma é possível reprogramar facilmente o seu processador atmega328p que é resposável por realizar todas as operações de comando que o Arduino realiza. A interface gráfica foi programada utilizando a linguagem Java que utiliza as bibliotecas ComRXTX para se comunicar com portas USB e Jfreechart para exibir os dados em um plano cartesiano na tela do computador, realizando assim a função graficar os dados em tempo real. A Figura2 mostra um exemplo de tela com dados de temperatura utilizando o esquema da Figura1. 


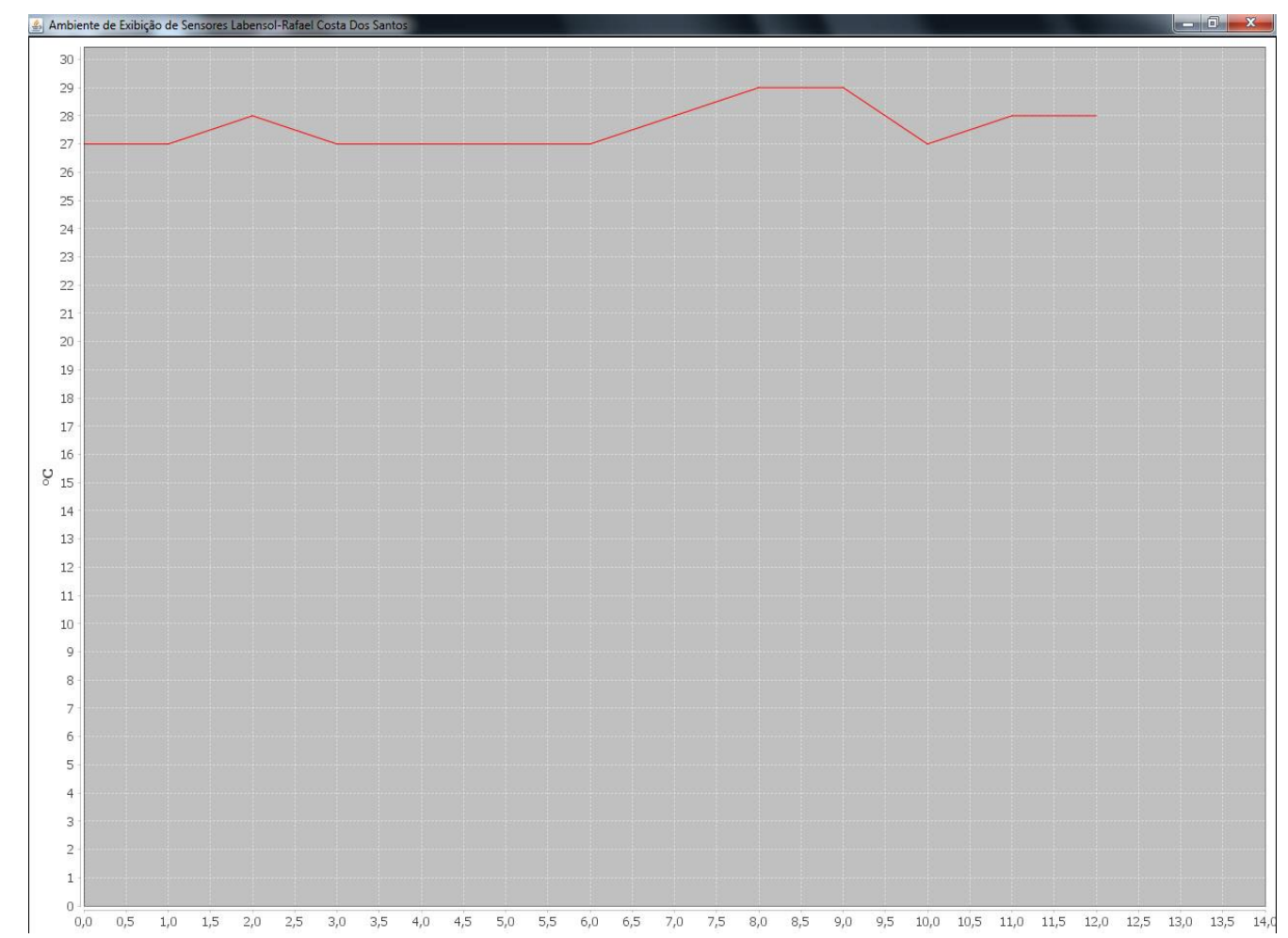

Figura2: Tela do gráfico exibindo os dados da temperatura em

função do tempo de amostragem.

\section{RESULTADOS ALCANÇADOS}

O teste de comunicação do computador e interface de exibição gráfica com o Arduino através de uma biblioteca ComRXTX em linguagem Java, tornou possível a elaboração de um software que consegue graficar dados vindo da porta USB, software este que demonstrou versatilidade e perspectiva de utilização em outras aplicações típicas de laboratórios experimentais.

\section{CONSIDERAÇÕES FINAIS}

$\mathrm{O}$ processo de aprendizagem em linguagem de programação e construção de software para interface de exibição gráfica foi muito útil e exclarecedor para entender técnincas que irão possibilitar o avanço na comunicação com o espectrômetro USB.

\section{REFERÊNCIAS}

1. C.A.Gueymard, Reference solar spectra: their evolution, standardization issues and comparison to recent measurements, Advances in Space Research, Vol.37, pp.323-340 (2006).

2. C.A.GUEYMARD, D.MYERS, K.EMERY. Proposed reference irradiance spectra for solar energy systems testing, Solar Energy, Vol.73, No.6, pp.443-467 (2002).

3. T, MUNEER.Solar radiation and daylight models, 2nd Ed., Elsevier (2004).

4. BARANIUK, JAMES; MELO, GRANEMAN, GLOVACKI, LUZ, JOÃO. Mini curso Arduino. HomePage: http://www.eletrica.ufpr.br / james/Laboratorio\%20V/arquivos/

Mini\%20Curso\%20Arduino.pdf. 
5.CAELUM. Java e a orientação a objetos. HomePage: https://www.caelum.com.br/download/ caelum-java-objetos-fj11.pdf.

6. INSTRUMENT TEXAS. LM35 PRECISON CENTIGRADE TEMPERATURE SENSORS. HomePage: http://www.ti.com/lit/ds/symlink/lm35.pdf. 